\title{
O TRABALHO EDUCATIVO E SUA RELAÇÃo COM A CONSTITUIÇÃO DA PERSONALIDADE HUMANA
}

\author{
EDUCATIONAL WORK AND ITS RELATIONSHIP WITH THE CONSTITUTION OF HUMAN \\ PERSONALITY
}

EL TRABAJO EDUCATIVO Y SU RELACIÓN CON LA CONSTITUCIÓN DE LA PERSONALIDAD HUMANA

\section{Tamini Wyzykowski \\ (iD) 9 \\ Mestrado em Educação nas \\ Ciências (UNIJUÍ) \\ Discente de Doutorado no \\ Programa de Pós-Graduação em \\ Educação nas Ciências (UNIJUÍ) \\ Bolsista da Coordenação de \\ Aperfeiçoamento de Pessoal de \\ Nível Superior (CAPES) \\ tamini.wyzykowski@gmail.com}

\section{Marli Dallagnol Frison (iD) 9}

Doutora em Educação (UFRGS)

Professora na Universidade

Regional do Noroeste do Estado

do Rio Grande do Sul (UNIJUÍ)

Docente no Programa de Pós-

Graduação em Educação nas

Ciências (UNIJUÍ)

marlif@unijui.edu.br

\begin{abstract}
Resumo
O artigo socializa compreensões acerca das implicações da educação escolar no desenvolvimento da personalidade humana, e teve por objetivo compreender e discutir a constituição desta personalidade e as implicações do trabalho educativo para o seu desenvolvimento mais pleno. A investigação é de natureza qualitativa e foi realizada a partir da Análise Textual Discursiva (ATD), em respostas registradas em questionário e entrevista. Estão incluídos neste estudo de caso sete professores da Educação Básica. Os dados foram analisados com apoio no referencial teórico da Psicologia Histórico-Cultural e da Pedagogia Histórico-Crítica. Resultados apontam a apropriação de conhecimentos científico-escolares e as relações sociais como fatores determinantes na constituição da personalidade humana. O estudo destaca que, via trabalho educativo, é possível redirecionar e potencializar a constituição da personalidade humana, pois, assim, são favorecidos o processo de aprendizagens de conteúdos e o estabelecimento de interações sadias entre alunos e professores, mediadas por instrumentos e signos.
\end{abstract}

Palavras-chave: Conhecimentos científico-escolares. Educação escolar. Relações sociais.

Recebido em: 2 de junho de 2021.

Aprovado em: 22 de agosto de 2021.

Como citar esse artigo (ABNT):

WYZYKOWSKI, Tamini; FRISON; Marli Dallagnol. O trabalho educativo e sua relação com a constituição da personalidade humana. Revista Prática Docente, v. 6, n. 2, e066, 2021.

http://doi.org/10.23926/RPD.2021.v6.n2.e066.id1205 


\section{Abstract}

The article socializes understandings about the implications of school education in the development of human personality. Its goal was to understand and discuss the constitution of this personality and the implications of the educational work for its fullest development. The investigation has a qualitative nature, and it was carried out with basis on the discursive textual analysis, with answers registered in questionnaires and interviews. Seven basic education teachers are included in this case study. The data was analyzed with support from the theoretical framework of Historical-Cultural Psychology and Historical-Critical Pedagogy. Results point to the appropriation of scientific school knowledge and social relations as determining factors in the constitution of human personality. The study highlights that, via educational work, it is possible to redirect and enhance the constitution of human personality because, this way, the content learning process and the establishment of healthy interactions between students and teachers, mediated by instruments and signs, are favored.

Keywords: Scientific school knowledge. School education. Social relations.

\section{Resumen}

El artículo socializa comprensiones acerca de las implicaciones de la educación escolar en el desarrollo de la personalidad humana, y tuvo por objetivo comprender y discutir la constitución de esta personalidad y las implicaciones del trabajo educativo para su desarrollo más completo. La investigación es de origen cualitativa y fue realizada a partir del Análisis Textual Discursiva (ATD), en respuestas registradas en cuestionario y entrevista. Están inclusos en este estudio de caso siete profesores de la Educación Básica. Los datos fueron analizados con apoyo en el referencial teórico de la Psicología Histórico Cultural y de la Pedagogía Histórico Crítica. Resultados apuntan la apropiación del conocimiento científico escolar y las relaciones sociales como elementos determinantes en la constitución de la personalidad humana. El estudio enfatiza que, a través del trabajo educativo, es posible redireccionar y potenciar la constitución de la personalidad humana, pues, así, son favorecidos el proceso de aprendizajes de contenidos y el estabelecimiento de interacciones sanas entre alumnos y profesores, intermediadas por instrumentos y signos.

Palabras clave: Conocimientos escolares. Educación escolar. Relaciones sociales. 


\section{INTRODUÇÃo}

No presente artigo socializamos compreensões acerca das implicações da educação escolar no desenvolvimento da personalidade humana. Com apoio em Vigotski (2012a,b), nesta pesquisa a personalidade é entendida como o desenvolvimento global do sujeito, aquilo que possibilita ao homem o domínio da própria conduta. Amparadas no autor, podemos afirmar que a personalidade é um elemento humano e subjetivo, pois, ao contrário de outras espécies, somente o homem desenvolve uma concepção própria de mundo, única em cada sujeito, que é manifestada nas ações conscientes no meio que ele vive. A escola, por sua vez, é um espaço social que precisa oferecer condições para que os alunos aprendam conhecimentos referendados socialmente e para que se constituam plenamente humanos no decurso dos processos educativos vivenciados (SAVIANI, 2013; DUARTE, 2011).

Situamos que inicialmente apresentaremos no texto alguns aspectos teóricos relacionados à formação da personalidade humana. Em seguida, descreveremos o contexto metodológico da investigação. Por fim, problematizaremos manifestações de professores atuantes na Educação Básica, expressas em questionário e entrevista, que vão ao encontro da temática central deste trabalho: implicações da educação escolar no desenvolvimento da personalidade humana.

Com base no referencial teórico da Psicologia Histórico-Cultural e da Pedagogia Histórico-Critica e partindo de interações estabelecidas com um grupo de professores da Educação Básica, temos como intencionalidade discorrer, ao longo do texto, a respeito da seguinte pergunta: Qual o papel da educação escolar na formação da personalidade humana?

A investigação que estamos sistematizando tem como objetivo principal compreender a constituição da personalidade humana e as implicações da educação escolar para o seu desenvolvimento mais pleno. Temos o pressuposto de que é necessário destinar um tempo e espaço nos currículos dos cursos de Licenciatura, bem como nos contextos de formação continuada, para promover discussões acerca desta temática. Esperamos que nosso trabalho indique possibilidades para refletir e melhor qualificar os processos formativos na docência, a fim de transformar os processos educativos nas escolas de Educação Básica, favorecendo a aprendizagem e a plena constituição da personalidade humana.

\section{A FORMAÇÃO DA PERSONALIDADE HUMANA: PRESSUPOSTOS TEÓRICOS}

É importante demarcar que para os estudiosos do referencial teórico da Psicologia Histórico-Cultural, o desenvolvimento da personalidade está intimamente relacionado à 
constituição social do ser humano. Vigotski (2012a, p. 328) define a personalidade como "um conceito social" que "engloba o que se sobrepõe ao natural, o histórico ao ser humano". Ele defende que a personalidade não é uma característica inata e sim um conceito histórico. Para o autor, o meio social é determinante na formação da personalidade, que pode ser compreendida como a concepção de mundo que o sujeito constituiu ou o domínio consciente de sua própria conduta.

Vigotski (2012a) assevera que uma concepção de mundo não pode ser explicada como um conceito universal, objetivo, num sistema de lógica. Quer dizer, cada pessoa tem sua própria concepção de mundo, ou uma conduta global a partir de relações que estabelece com elementos da cultura que foram significados, tornando-se determinantes na formação do psiquismo. Em tempo, neste espaço oportuno é importante sinalizar a relevância de um breve entendimento sobre os termos "cultura" e "significação", pois são dois conceitos intimamente relacionados e necessários à compreensão da personalidade, recorrentes no enfoque da Psicologia HistóricoCultural.

Nessa matriz teórica, a cultura é considerada um produto da humanidade. Sirgado (2000, p. 54) esclarece que "para Vigotski a cultura é a totalidade das produções humanas (técnicas, artísticas, científicas, tradições, instituições sociais e práticas sociais). Em síntese, tudo que, em contraposição ao que é dado pela natureza, é obra do homem”. Sendo assim "a natureza da cultura está relacionada com o caráter duplamente instrumental, técnico e simbólico, da atividade humana" (Idem). A significação, por sua vez, em concordância com Leontiev (1978, p. 94),

[...] é aquilo que num objeto ou fenômeno se descobre objetivamente num sistema de ligações, de interações e de relações objetivas. A significação é refletida e fixada na linguagem, o que lhe confere a sua instabilidade. Sob a forma de significações linguísticas, constitui o conteúdo da consciência social; entrando no conteúdo da consciência social, torna-se assim a "consciência real" dos indivíduos, objetivando em si o sentido subjetivo que o refletido tem para eles.

Prosseguindo nossa linha de sistematização, para Vigotski e Luria (1996) a formação da personalidade está relacionada com a psicologia do homem cultural adulto, que envolve três trajetórias evolutivas complexas: a evolução biológica, a evolução histórico-cultural e o desenvolvimento individual de uma personalidade específica. Isso revela que, em outras palavras, quando estudamos a formação da personalidade concomitantemente temos de lembrar e refletir sobre o "desenvolvimento do macaco até o homem, do homem primitivo até o representante da era cultural e da criança até o adulto" (VIGOTSKI; LURIA, 1996, p. 151). 
Em sua obra, Vigotski (2012a) discorre sobre como se dá o desenvolvimento humano cultural em diferentes idades a fim de explicar a constituição da personalidade. Ele pressupõe que na infância existem três períodos relacionados à formação de uma concepção de mundo infantil: recém-nascido, idade lúdica e idade pré-escolar.

Segundo Vigotski (2012a, p. 331), o recém-nascido é a fase mais primitiva do humano, em que a criança apresenta um comportamento que tem como base "os instintos, os reflexos condicionados e as formas mais simples de pensamento". Nesta fase acontece um período de transição da vida natural para a vida cultural, também denominado pelo autor de uma fase "mágica", na qual a criança começa a explorar o ambiente cultural, sendo esse um processo intermediado por adultos e mediado por instrumentos e signos.

Os signos são produto da atividade humana e derivam, portanto, da história da humanidade (VIGOTSKI, 2012a). São utilizados pelas pessoas para estabelecer comunicação e constituir relações sociais no meio cultural. Vigostki (2012a) explica que o contato com signos e instrumentos do mundo externo possibilitam à criança se desenvolver culturalmente. Signos e instrumentos podem ser compreendidos como recursos psicológicos estruturados socialmente, que viabilizam a interação e a significação de elementos culturais.

Um importante signo é uma palavra com um significado social que tem uma ação constitutiva no intelecto do homem em todos os processos psicológicos, auxiliando na apropriação da cultura (VIGOTSKI, 2008). Nesse seguimento, Smolka (2004, p. 42) destaca "a palavra como signo por excelência, como modo mais puro e sensível de relação social e ao mesmo tempo, material semiótico da vida interior" (p. 42).

Signos e instrumentos "são meios que orientam o comportamento humano de diferentes maneiras, permitindo ao indivíduo controlar e transformar o ambiente físico e social do qual ele é parte integrante, como também controlar e transformar seu próprio comportamento" (SILVA, 2013, p. 2). Smolka (2000, p. 30) especifica que

\begin{abstract}
se existe uma distinção crucial na orientação das atividades (instrumentos são dirigidos "para fora"; signos são dirigidos "para dentro"), queremos ressaltar que os instrumentos se caracterizam geralmente por sua finalidade e especificidade, enquanto os signos, na sua materialidade simbólica, são marcados por uma não especificidade (caráter difuso, contornos embaçados), pela impregnação (caráter seminal e "permeante") e pela reversibilidade (direcionados para o outro e para si).
\end{abstract}

Em suma, dito em outras palavras, signos e instrumentos são elementos mediadores que possibilitam a comunicação entre os sujeitos e, com isso, a socialização e a aprendizagem de conhecimentos produzidos e referendados ao longo da história da humanidade. No vocábulo de 
Silva (2013, p. 2), são “mediadores da atividade prática e da atividade psicológica do indivíduo humano, havendo uma ligação real entre eles tanto na história da evolução da espécie humana quanto no desenvolvimento de cada indivíduo". Eles permitem ao homem desenvolver o próprio pensamento, bem como organizar, intencionalizar e controlar suas ações de um modo consciente. A partir de signos e instrumentos, os adultos realizam mediatização da cultura para as crianças. Assim, podemos afirmar que signos e instrumentos são determinantes no desenvolvimento infantil e na formação da personalidade.

Vigotski (2012a) reitera que as ações da criança durante o primeiro estágio não revelam uma concepção de mundo, pois seu psiquismo é elementar e biológico. O recém-nascido é totalmente dependente dos outros para sobreviver e está se inserindo num contexto social até então desconhecido. Conforme vai crescendo, a criança aprende a se locomover, engatinhar e caminhar, o que lhe permite explorar o espaço, se movimentar no ambiente com autonomia e manipular diferentes objetos. Aos poucos, ela se apropria da linguagem externa, manifesta gestos em direção aos objetos para chamar a atenção dos adultos e, posteriormente, vai aprendendo a dominar seu espaço a partir dos signos, como as palavras.

Para Vigotski (2012a), o principal evento relacionado ao desenvolvimento da personalidade infantil está relacionado ao instante em que a criança reconhece a si mesma, compreende seu nome e quem ela é a partir dos outros, tomando consciência do seu próprio "eu". O reconhecimento de si envolve fatores afetivos e cognitivos, significados a partir do mundo externo. Com isso, o autor (p. 337) ensina que "o conceito de personalidade é social, é um conceito reflexo que a criança forma aplicando a si mesma os procedimentos de adaptação que aplica aos outros. Podemos, portanto, dizer que a personalidade é o social em nós”. Sendo assim, a personalidade vai se constituindo individual a partir do social, pois "a criança domina um ou outro processo de conduta seguindo o exemplo de como o adulto domina este processo" (Idem).

Na sequência, Vigotski (2012a) apresenta que a idade lúdica é a fase posterior de desenvolvimento da concepção do mundo infantil. Para ele, neste estágio a criança tem facilidade para dominar e diferenciar instrumentos e signos. Isso a direciona para uma nova conduta, na qual os jogos assumem um importante papel, estabelecendo relações psicológicas e físicas. O brinquedo, para Vigotski (2007, p. 118), “cria na criança uma nova forma de desejos. Ensina-a a desejar, relacionando seus desejos a um 'eu' fictício, ao seu papel no jogo e suas regras". Nos jogos, ou nos brinquedos, a criança manifesta sentimentos, valores e 
compreensões advindas do contexto social em que está inserida; ela pode imaginar e elaborar brincadeiras, também pode brincar de ser outra pessoa - o "faz de conta". O brincar viabiliza para a criança "aquisições que no futuro tornar-se-ão seu nível básico de ação real e moralidade" (Idem).

Em seguida, conforme Vigostki (2012a, p. 338), a criança desenvolve-se na fase de idade escolar, na qual ela começa a constituir uma concepção de mundo infantil "mais estável e consistente". A inserção na escola estimula a formação de uma personalidade infantil, pois é um contexto com diversas e diferentes experiências sociais que estimulam a constituição do sujeito. A partir da idade escolar, o "pensamento e a ação se separam visivelmente", pois a criança "vive em uma esfera de percepção e ação diretas. [...] Esta criança já é consciente de seus atos, os planeja graças aà linguagem" (Ibidem, p. 339).

O ambiente escolar oferece condições favoráveis para que a criança domine o percurso do próprio pensamento, pois "cria uma provisão da experiência, implanta grande número de métodos auxiliares complexos e sofisticados e abre inúmeros novos potenciais para a função humana social" (VIGOTSKI; LURIA, 1996, p. 194). De acordo com Bozhóvich (1987, p. 264), a escola direciona a criança a tomar consciência do seu eu social, possibilitando um novo nível de autoconsciência, e "precisamente esta nova estrutura determina sua conduta e atividade e todo o sistema de suas relações na realidade, em relação a si mesmo e em relação às pessoas ao seu redor". Nas crianças em idade pré-escolar “estão mediatizados sobretudo, pelos modelos de comportamento e atividade dos adultos, suas inter-relações, as normas sociais estabelecidas nas instâncias morais correspondentes" (Ibidem, p. 269). Com isso, podemos depreender que a escola é um contexto social importante para o desenvolvimento das crianças. $\mathrm{O}$ desenvolvimento da personalidade em sua totalidade, conquanto, não se completa na idade infantil, mas se dá maiormente na adolescência.

Seguindo a linha de pensamento, a matriz teórica que embasa nossa pesquisa destaca que é no período da adolescência, a partir dos 12 anos, que ocorrem mudanças psíquicas essenciais que resultam e determinam a plena formação da personalidade. Consoante Vigostki (2012b), no período da adolescência desencadeia-se uma série de transformações psíquicas e biológicas que refletem em mudanças na estrutura da personalidade, possibilitando diferenciar a personalidade infantil da personalidade do adolescente. $\mathrm{O}$ autor explica que na adolescência ocorre uma reestruturação externa e interna no sujeito. Nesse período o sujeito começa a manifestar seus interesses, e um momento determinante de sua vida é o de decidir sua futura 
profissão, o que revela a sua concepção de mundo. Também acontece a maturação sexual biológica e se desenvolvem, em âmbito mais complexo, as funções mentais superiores, que possibilitam o pensamento por conceitos e as tomadas de decisão e ação mais conscientes. Isso explica a premissa de que "o desenvolvimento não é simples maturação, mas sim metamorfose cultural, reequipamento cultural" (VIGOTSKI; LURIA, 1996, p. 194).

Para Vigotski (2012b), a formação da personalidade na adolescência tem como núcleo central o desenvolvimento, na esfera das máximas potencialidades humanas, das funções mentais superiores. Função Mental Superior (FMS) ou Função Psíquica Superior (FPS), de acordo com explicações do autor, é o resultado de uma série de processos fisiológicos e psicológicos em que as funções elementares da mente humana, como memória e atenção, são combinadas com novas atividades. O desenvolvimento sociocultural viabiliza uma evolução psíquica; é um processo histórico que possibilita ao homem a capacidade de fazer algo a mais junto as atividades elementares. A partir da adolescência a memória elementar transforma-se em memória superior, a atenção constitui-se em atenção voluntária, e também se modificam o pensamento por conceitos, a linguagem, a percepção e as demais funções superiores (VIGOTSKI, 2012b).

Ao encontro disso, Bozhóvich (1987) reforça que a desintegração dos elementos constitutivos das funções psíquicas superiores ocasiona o desaparecimento das suas especificidades, resultando em danos para o psiquismo do sujeito. Nas palavras desse autor (p. 250), "uma vez surgidas, as FPS se convertem em neoformações estáveis, cuja desintegração pode ocorrer somente na velhice ou como resultado de um processo patológico". Vigotski (2012a) explica que a personalidade se constitui junto com a formação de cada uma das funções superiores, e que elas dependem umas das outras para o pleno desenvolvimento psíquico humano:

\begin{abstract}
A linguagem, meio fundamental para o desenvolvimento da personalidade, conduznos à principal forma de memória superior que só se torna compreensível à luz da função indicadora dos signos da atenção. A palavra é a ferramenta direta de formação de conceito. A linguagem é o meio fundamental do pensamento e está ligada ao desenvolvimento do gesto, do desenho, do brincar e da escrita. A atenção, por sua vez, nos fornece a base necessária para o desenvolvimento de conceitos que, sem ela, não seriam claros (p. 329-330).
\end{abstract}

Com isso, o autor enfatiza que não é possível compreender a formação da personalidade sem o desenvolvimento das funções mentais superiores, o que reforça sua tese de que o homem não possui personalidade ao nascer, mas a desenvolve ao longo da sua vida, num processo histórico-social (VIGOTSKI, 2012a). 
Vigotski (2012b) propõe que três leis fundamentais regem a formação da personalidade na adolescência. A primeira lei diz que o núcleo central do desenvolvimento da personalidade envolve a "transição de formas e modos de comportamento natural, imediatos, espontâneos aos mediados e artificiais que surgem no processo de desenvolvimento cultural das funções psíquicas" (p. 226).

De acordo com Vigotski (2012b), o comportamento do homem transforma-se à medida que ele aprende a dominar suas próprias operações psíquicas, a partir de signos e instrumentos sociais. Isso quer dizer que a personalidade está relacionada com o desenvolvimento histórico da conduta humana. Nas palavras de Vigostki e Luria (1996, p. 219): “o comportamento natural torna-se comportamento cultural; técnicas externas e signos culturais aprendidos na vida social tornam-se processos internos". Como exemplo, podemos citar quando o sujeito registra uma palavra na mão para lhe auxiliar a lembrar de algo. Neste contexto, o sujeito domina sua memorização, transformando a memória imediata em memória mediada a partir de um meio artificial. "Essa primeira lei, portanto, consiste na transformação das funções imediatas, espontâneas, às funções mediadas e intencionais" (ANJOS, 2017, p. 124).

A segunda lei envolvida no desenvolvimento da personalidade do adolescente é a premissa de que

as relações entre as funções psíquicas superiores foram em tempos relações reais entre os homens: no processo de desenvolvimento das formas coletivas e sociais de comportamento se convertem modos de adaptação individual, formas de conduta e de pensamento da personalidade (VIGOTSKI, 2012b, p. 226).

A partir desse pressuposto, vale considerar que vivemos ou frequentamos diferentes contextos, como a família, o bairro, a igreja e a escola. As regras coletivas que sustentam esses espaços sociais, como as concepções de ética, moral e bom senso, são apropriadas na constituição do pensamento dos sujeitos. A linguagem é uma função mental superior e uma ferramenta de comunicação e constituição que possibilita organizar o comportamento das pessoas num determinado tempo e espaço, estruturar o pensamento e atuar na formação da personalidade (VIGOTSKI, 2012b).

Conforme Vigotski (2012a,b), o pleno desenvolvimento das funções psíquicas é influenciado pelas relações sociais que se estabelecem nos espaços culturais. As relações sociais também são, portanto, uma base para a formação da personalidade. "A natureza da personalidade é social. [...] A natureza psíquica do homem é um conjunto de relações sociais transportadas para o interior, e convertidas em funções da personalidade, parte dinâmica de sua estrutura" (VIGOTSKI, 2012b, p. 228). Os diferentes sujeitos e comportamentos sociais 
presentes na sociedade, implicam formação de uma conduta individual, uma personalidade humana. Em suma, como bem desvenda Anjos (2017, p. 125), “a natureza da personalidade é cultural. Todas as funções psíquicas superiores são relações de ordem social que, ao serem internalizadas, constituem a base da estrutura da personalidade".

Por fim, Vigotski (2012b, p. 229) apresenta a terceira lei, a qual presume que a personalidade se desenvolve porque o homem vai "transformando funções de fora para dentro". Ao explicar que signos são sempre externos e depois passam a ser internos, o autor ensina que o comportamento social é um fator externo que passa a ser interno em cada sujeito. Nesse sentido, nós "nos convertemos em nós mesmos através de outros” (Idem).

A partir da adolescência, quando se formam as funções superiores, quando se constitui o pensamento por conceitos, o sujeito tem a capacidade de dominar a própria conduta e tomar decisões conscientes. É importante ter clareza que as FMSs se formam no decorrer do desenvolvimento humano; trata-se de um processo que vai "acontecendo", e, conforme o contexto social, vai se desenvolvendo o cultural em cada sujeito. Concomitantemente a isso, o domínio da própria conduta forma o caráter interno das FMSs, e, nesse processo, o homem vai se convertendo em personalidade.

Vigotski (2021b, p. 230) salienta que o domínio da própria conduta pressupõe que o sujeito tenha controle do "reflexo da consciência, reflexo em palavras da estrutura das próprias operações psíquicas" e que isto está relacionado com uma vontade de liberdade, uma "necessidade epistemológica", que estimula a realização de ações voluntárias. Sendo assim, se o adolescente tiver vontade de aprender um conteúdo escolar, por exemplo, ele poderá manifestar a conduta de elencar ações de estudo para alcançar o objetivo. "A vontade subjacente à formação da personalidade é, afinal de contas, a primeira forma de conduta". A conduta do sujeito é uma ação verbal, resultante da metamorfose da linguagem primitiva em função superior (Idem).

Segundo Vigotski (2012b), a autoconsciência não é uma característica biológica ou primitiva da espécie; ela desenvolve-se a partir do contexto social, que é fator determinante na constituição da personalidade. Sendo assim, o sujeito constitui uma conduta social em relação aos outros que se relaciona a si mesmo. Então, a terceira lei considera, fazendo alusão à locução de Anjos (2017, p. 126-127), que "a base da formação da personalidade é a transferência das relações sociais externas ao interior, as quais são convertidas em funções da personalidade". Vale ressaltar que essa "transferência" não é direta, é mediada, pois os elementos do meio 
social, ao serem internalizados, passam a integrar e formar uma rede de sentidos e significações na mente humana e se constituindo culturalmente no psiquismo.

A tomada de consciência, todavia, das próprias ações e da conduta no meio social, bem como o domínio e a articulação das operações psíquicas, são processos que demoram a se manifestar no ser humano. O processo inicia na adolescência, sua culminação se dá no início da vida adulta e resulta na personalidade do sujeito. Nesse seguimento, Bozhóvich (1987, p. 251) enfatiza que

\begin{abstract}
a personalidade psicologicamente madura é o homem que atingiu um certo alto nível de desenvolvimento psíquico. Como característica fundamental desse desenvolvimento, apontamos o surgimento, no homem, da capacidade de se comportar independentemente das circunstâncias que o atuem imediatamente (e mesmo contra elas), sendo guiado por seus próprios objetivos, conscientemente traçados. O surgimento de tal capacidade condiciona o caráter ativo, e não reativo, do comportamento do homem e o torna não escravo das circunstâncias, mas dono delas e de si mesmo.
\end{abstract}

As considerações dos autores, apresentadas até aqui, permitem avaliar que a personalidade assegura ao homem, de modo consciente, a direção, o controle e a autorregulação das ações e do comportamento, e que a escola pode desempenhar um importante papel no desenvolvimento psíquico de crianças e adolescentes, especialmente se entendermos que "o domínio da conduta implica consciência das próprias ações e, no caso da adolescência, tal processo se efetiva por meio do pensamento por conceitos" (ANJOS, 2017, p. 126-127).

Com apoio em Anjos (2017), reconhecemos que existem importantes implicações psicológicas e pedagógicas imbricadas no pleno desenvolvimento da personalidade humana. Para este autor (p. 128), a educação escolar contribui na formação da personalidade "por meio da transmissão-assimilação dos conteúdos sistematizados, possibilitando o desenvolvimento do pensamento por conceitos que é, por sua vez, a condição para o desenvolvimento do autodomínio da conduta, da autoconsciência e da concepção de mundo". É nessa direção que conduziremos o enredo do presente artigo, atrevendo-nos a tentar contribuir com a discussão e socializar compreensões sobre a temática.

\title{
3 Metodologia
}

Este trabalho insere-se na abordagem qualitativa de pesquisa na área da Educação, na modalidade de Estudo de Caso (LÜDKE; ANDRÉ, 1986; YIN, 2001). O percurso investigativo tem como base o princípio de pesquisa descrito por Maldaner (1999), o qual sugere que

o exercício da pesquisa é uma qualidade eminentemente humana, desenvolvida na cultura e na história humana. Através dela o ser humano criou instrumentos práticos e teóricos que lhe permitem agir e pensar de uma certa forma sobre a natureza e obter 
as respostas desejadas. Com ela mudaram as relações dos homens com a natureza, mudou o homem e mudaram as relações entre os homens. Porém, como prática cultural e histórica, a pesquisa não é uma herança biológica, assim como não são os conceitos científicos e toda a prática científica e tecnológica. Elas devem ser construídas e reconstruídas junto a cada indivíduo nos processos educacionais ( $\mathrm{p}$. 290).

O estudo que estamos socializando faz parte de uma pesquisa de Doutorado e se constituiu junto a um projeto aprovado pelo Comitê de Ética em Pesquisa da Universidade Regional do Noroeste do Estado do Rio Grande do Sul (UNIJUÍ). Todos os participantes assinaram o Termo de Consentimento Livre e Esclarecido (TCLE), seguindo as orientações previstas na Resolução n ${ }^{\circ}$ 510/2016 (BRASIL, 2016) do Conselho Nacional de Saúde (CNS). A investigação foi realizada no contexto de uma escola da rede pública estadual localizada no município de Ijuí, no Estado do Rio Grande do Sul (RS), Brasil (BR). Estão envolvidos nesta investigação sete professores que lecionam no Ensino Médio, atuando em disciplinas relacionadas com sua formação inicial: (2) Língua Portuguesa, (1) Biologia, (2) Química, (1) História e (1) Sociologia.

A construção dos dados envolveu o desenvolvimento de questionário e entrevista, com perguntas abrangendo as temáticas de ensino, aprendizagem, função social da escola e constituição da personalidade humana e do ser professor. O questionário foi respondido pelos professores em 2019. A opção por esse instrumento metodológico justifica-se pelo fato de ele possibilitar aos sujeitos implicados a expressão de ideias e, ao mesmo tempo, contribuir para o pesquisador identificar concepções sobre o tema abordado no campo empírico.

A entrevista, por sua vez, foi previamente agendada com cada um dos professores que aceitou participar da pesquisa e foi realizada individualmente no ano de 2020. Em decorrência da necessidade de manter o distanciamento social durante a pandemia da Covid-19, as entrevistas desenvolveram-se a partir do serviço de comunicação Google Meet, que possibilitou o registro audiovisual do conteúdo, o qual foi transcrito posteriormente.

Para Lüdke e André (1986, p. 34), “a vantagem da entrevista sobre outras técnicas é que ela nos permite a captação imediata e corrente da informação desejada, praticamente com qualquer tipo de informante e sobre os mais variados tópicos”. Além disso, a realização da entrevista com os professores permitiu o aprofundamento de algumas ideias que eles registraram no questionário em 2019. Assim, ao encontro do que explicam Lüdke e André (1986, p. 34), a entrevista constituiu-se como um instrumento metodológico que "permite correções, esclarecimentos e adaptações que a tornam sobremaneira eficaz na obtenção das informações desejadas". 
O corpus textual produzido a partir da digitalização das respostas do questionário e da transcrição das entrevistas, foi organizado com base na Análise Textual Discursiva (ATD) proposta por Moraes e Galiazzi (2011). Segundo estes autores, a ATD auxilia a interpretar os discursos em pesquisas qualitativas e envolve a realização das etapas de unitarização, categorização e captação do novo emergente no corpus textual do material empírico. De acordo com Copetti et al. (2020, p. 103),

a ATD instiga o pesquisador a pensar sobre os múltiplos e desafiadores caminhos na construção do trabalho, permite o encontro com o fenômeno a ser investigado que, muitas vezes, não se apresenta claramente de imediato, mas que se descortina a partir dos movimentos que são realizados durante a análise. Movimentos estes, que não apresentam um sentido único e uma regra imutável para sua execução. São próprios, únicos e imbuídos da personalidade de cada pesquisador no modo de fazer.

A interpretação dos resultados, facilitada pelo viés da ATD, foi sistematizada com apoio teórico no referencial da Psicologia Histórico-Cultural e da Pedagogia Histórico-Crítica (VIGOTSKI, 2007; MARTINS, 2013; SAVIANI, 2013; DUARTE, 2011; ANJOS, 2017). Para manter o sigilo e o anonimato dos sujeitos da investigação, conforme determina o código de ética em pesquisa com seres humanos (BRASIL, 2016), atribuímos nomes fictícios com a letra inicial $\mathrm{P}$ aos professores envolvidos. Na tessitura do texto, as expressões dos participantes aparecem destacadas em itálico. Por conseguinte, passamos a compartilhar algumas discussões sobre possíveis contribuições da educação escolar na formação da personalidade humana.

\section{Análise e Discussão dos ReSultados}

A análise de dados revela, de modo geral, que os professores envolvidos nesta pesquisa concebem a escola como um contexto social que favorece a constituição da personalidade humana. Priscila assim explicou no questionário:

A educação pode interferir na formação da personalidade das crianças e dos jovens, pois, estes frequentam o ambiente escolar, sentem-se intimamente ligados a ele. A educação escolar influencia o jovem a buscar uma profissão, um saber mais apurado e consequentemente uma vida econômica mais estável (Priscila Questionário, 2019).

A manifestação de Priscila, defendendo a importância da escola para a formação dos alunos, vai ao encontro da problematização que nos propomos a desenvolver nesta escrita. Junto disso, outras expressões advindas da investigação evidenciam, no entanto, que nem sempre os professores têm a plena consciência do quanto o seu papel profissional implica desenvolvimento da personalidade, à medida que eles não reconhecem a dimensão da relevância do seu próprio trabalho para a formação psíquica de seus alunos. Essa ideia pode ser identificada na fala de Pietra: 
“é... que na verdade, o aluno já chega, assim, como é que a gente vai dizer, com a sua personalidade na escola, não é? Ele pode... a gente consegue, muitas vezes, moldar ele com alguns aspectos na questão de valores, em questão de respeito... mas a personalidade em si, eu acho que... não... isso ele já traz dele, de casa, não é?, de formação da personalidade dele. É claro que você contribui muito, você consegue, se ele está aberto a isto, a receber, não é?, consegue... não vou dizer... ninguém consegue moldar uma pessoa, mas você consegue contribuir pra que ele consiga ser melhor, de uma certa forma, não é? Mas eu acho que ele já vem sim com a personalidade dele bem... ainda mais eu, no Ensino Médio, não é? Ele já passou por uma caminhada ali na escola; eles trazem muitas heranças das outras escolas. E a gente, principalmente no $1^{\circ}$ ano, a gente tem que trabalhar isso pra que eles tenham aquela postura de Ensino Médio, que eles têm que ter uma postura diferente na escola, e tudo... mas eles já trazem... cada um tem a sua personalidade ali bem definida" (Pietra - Entrevista, 2020).

A manifestação de Pietra convida a pensar sobre a necessidade de o professor ter conhecimentos sobre como os alunos aprendem e como se dá o desenvolvimento da personalidade humana. Nessa direção, com apoio em Saviani (2013), Marsiglia e Saccomani (2016) discutem que

o desenvolvimento de seres humanos não acontece de modo natural, linear e espontâneo, mas tão somente por meio da apropriação da cultura. Trata-se de um desenvolvimento histórico-cultural e, portanto, é resultado da produção (ou não) na subjetividade de cada indivíduo, daquilo que já foi produzido no mundo da cultura pela humanidade ao longo da história (p. 243).

Pensando nisso, podemos mencionar que quando Pietra expressa que "o aluno já chega, assim, como é que a gente vai dizer, com a sua personalidade na escola", ela parece não conceber que a etapa de escolarização se constitui em um período no desenvolvimento histórico-cultural de cada sujeito, que implica transformação intelectual dos alunos, ou, em outras palavras, como já foi anteriormente destacado por Priscila, que "a educação pode interferir na formação da personalidade das crianças e dos jovens". Delineamos, todavia, que é imprescindível associar a qualidade da educação escolar com as reais condições de viabilizar uma formação humana mais plena, ao mesmo tempo em que não é qualquer processo de ensino e de aprendizagem que contempla a todos ou que privilegia a aprendizagem conceitual e o desenvolvimento psíquico de cada aluno. Conforme ressaltam Marsiglia e Saccomani: "a qualidade das condições objetivas de vida e educação produz e determina a subjetividade dos sujeitos. Assim sendo, o desenvolvimento psíquico não pode ser desvinculado da maneira como o ser humano está inserido na sociedade" (2016, p. 243).

Primar pela qualidade dos processos educativos que se desencadeiam nos contextos escolares é primordial para se constituir relações sadias, aprendizagens e desenvolvimento humano. A escola tem um papel social determinante na constituição da personalidade à medida 
que ela é um contexto que deve socializar e significar, de modo sistematizado e intencional, diferentes conhecimentos produzidos na sociedade e referendados culturalmente.

Ademais, não podemos ignorar que a escola está inserida em uma sociedade capitalista e que isso implica qualidade da educação. Seguindo essa linha de pensamento, a literatura da área e algumas expressões dos sujeitos da pesquisa apontam para a necessidade de ocorrer uma transformação histórica da escola, como defende Saviani (2013). A fala de Pedro ilustra essa ideia: "a escola reproduz tudo que há de errado! A escola é uma microssociedade e a sociedade é um instrumento que reproduz. [...] Se toda sociedade passa pela escola, por que a sociedade fica pior?" (Pedro - Entrevista, 2020).

A partir da manifestação de Pedro podemos refletir que se constitui um grande desafio para a escola potencializar a plena constituição da personalidade, especialmente levando em conta toda a diversidade de pessoas de diferentes classes sociais, crenças e hábitos que se inserem neste espaço social de promoção da cultura. É perceptível nos discursos dos participantes desta investigação que, em relação ao desenvolvimento da sociedade como um todo, muita responsabilidade é atribuída à escola e aos professores. Por hora, considerando que a escola pode contribuir para a formação da personalidade e que diferentes personalidades formam a sociedade, vale minimamente ter o entendimento de que a escola surgiu a partir da sociedade e tem por princípios transformar a própria sociedade que instituiu sua existência. Em suma, convém assimilar que "a transformação da escola é dependente da transformação da sociedade, de modo que possa atender a todos, em igualdade" (MARSIGLIA; SACCOMANI, 2016, p. 365).

Nas manifestações dos professores identificamos que há uma identificação do papel da escola para a constituição da personalidade humana, e, a partir disso, para a transformação da sociedade. Seguindo os pressupostos metodológicos da ATD, de Moraes e Galiazzi (2011), foi possível selecionar no corpus textual desta pesquisa duas categorias relacionadas às contribuições da educação escolar na formação da personalidade: (I) conhecimento e (II) relações sociais.

A apropriação do (I) conhecimento foi apontada pelos professores envolvidos como uma contribuição que a escola oferece para possibilitar a constituição da personalidade. Alguns deles defendem a importância da aprendizagem de conceitos científicos para melhor formar seus alunos, como podemos analisar na fala de Patrícia:

"Eu acredito muito. Principalmente, não é? na nossa área que, que eu sempre incentivo a leitura, não é? eu sempre... as artes, assim, em geral, sempre é uma influência na 
personalidade. Então, tudo que é positivo, que é a leitura, vai influenciar na personalidade, na... no amadurecimento, não é, que eles, pra eles... e outra questão assim, que é difícil, que eles não gostam muito de ler, não é, tudo que é muito extenso, que exigem um pouquinho mais, eles não... são meio... então, quando a gente consegue envolver eles numa leitura, numa atividade, vai ajudar a formar a personalidade" (Patrícia - Entrevista, 2020).

As expressões de Patrícia convidam a pensar sobre a relevância de o professor assumirse como gestor e intermediador dos processos de ensino e de aprendizagem. Para tanto, independente da área de formação inicial, os docentes precisam ter consciência dos conhecimentos que os alunos precisam e podem aprender, considerando a idade, a série escolar e o período histórico-cultural que eles estão vivenciando, para poder avançar no desenvolvimento social e individual de cada sujeito (MARSIGLIA; SACCOMANI, 2016). Ademais, Eidt e Duarte (2007) esclarecem que

o conhecimento científico não equivale a um mero somatório de classificações e conceituações das várias ciências, mas é uma síntese da atividade material e intelectual produzida pelas gerações anteriores. Sua apropriação está estritamente ligada a uma efetiva reorganização dos processos psíquicos das crianças, ou seja, a um aumento na qualidade de generalizações conceituais que a aprendizagem confere ao pensamento, ao surgimento de formas especiais de conduta, à modificação da atividade das funções psíquicas e à criação de novos níveis de desenvolvimento humano (p. 55-56).

Com apoio em Vigotski (2007) e Saviani (2013), podemos depreender que para haver aprendizagem de conhecimentos científicos e constituição da personalidade no âmbito escolar, o professor necessita produzir um trabalho educativo e agir na Zona de Desenvolvimento Proximal (ZDP) de seus alunos. Para Vigostki (2007), a escola deve oferecer as condições necessárias para produzir aprendizagens que garantam o desenvolvimento dos alunos. A ZDP é definida por este autor (p. 97) como "a distância entre o nível de desenvolvimento real”, que são os conhecimentos do meio social já apropriados pela criança, "e o nível de desenvolvimento potencial", que são os conhecimentos que a criança poderá internalizar com o auxílio de alguém mais experiente. Ele explica que "a ZDP define aquelas funções que ainda não amadureceram, mas que estão em processo de maturação, funções que amadurecerão, mas que estão presentemente em estado embrionário" (p. 98). Nesse sentido, é fundamental que os professores tenham clareza que o "bom aprendizado", que é função da escola promover junto aos alunos, "é somente aquele que se adianta ao desenvolvimento" (Ibidem, p. 102).

Em relação ao trabalho educativo, por sua vez, Saviani (2013) discorre que ele pode ser compreendido como

o ato de produzir, direta e intencionalmente, em cada indivíduo singular, a humanidade que é produzida histórica e coletivamente pelo conjunto dos homens. 
Assim, o objeto da educação diz respeito, de um lado, à identificação dos elementos culturais que precisam ser assimilados pelos indivíduos da espécie humana para que eles se tornem humanos e, de outro lado e concomitantemente, à descoberta das formas mais adequadas para atingir esse objetivo (p. 13).

O trabalho educativo, por indicar caminhos e direções para alcançar o desenvolvimento humano, torna-se um fator determinante na constituição da personalidade MARSIGLIA; SACCOMANI, 2016). Ao promover o trabalho educativo na educação escolar, é imprescindível questionar os conhecimentos que devem ser apropriados pelos alunos e as formas de o professor organizar o ensino, pois, "para que haja aprendizagem e desenvolvimento, há que existir ações educativas intencionalmente orientadas a essa finalidade" (Ibidem, p. 347). Em outras palavras, podemos afirmar que os conhecimentos científicos problematizados no percurso do trabalho educativo devem favorecer e potencializar a humanização de cada sujeito, que incide na constituição da personalidade. Nesse sentido, Anjos (2017, p. 11) salienta que "os conteúdos sistematizados, os conteúdos clássicos, ao serem internalizados pelo aluno, possibilitam o desenvolvimento do pensamento por conceitos, base sobre a qual se formam as sínteses superiores da personalidade e da concepção de mundo".

Ao encontro dessas impressões, identificamos algumas manifestações advindas do campo empírico. Para Priscila, por exemplo, o conhecimento discutido na escola é importante para a formação da personalidade...

\begin{abstract}
...porque têm alunos, claro que eles já vêm, eu já pego adolescentes, não é? Então, eles já estão formando a sua personalidade, já trazem bastante coisas de casa, não é? Mas, tu vais trabalhando com eles, tu vais incentivando eles, e eles vão começando ter novos pensamentos, eles vão começando a buscar novas coisas pra vida deles. Então, vai formando uma personalidade mais desenvolvida, uma pessoa que quer buscar mais coisas na vida, não é? Se não, tem aqueles que também, claro, que nem sempre gostam de estudar. Mas a gente sempre está motivando os alunos, sempre correndo atrás dos alunos, não é? Para que eles sejam melhores. Eu sempre digo para eles: "vocês têm que ser melhores que os pais de vocês! Não que os pais não sejam bons, mas se teu pai tem faculdade, você tem que ter Mestrado, tem que ter Doutorado, tem que correr atrás das coisas, tem que ser melhor que os pais!" Eu sempre falo isso para eles. (Priscila - Entrevista, 2020).
\end{abstract}

Em sua fala, Priscila destaca que a educação escolar influencia no desenvolvimento humano e na formação da personalidade dos alunos. O referencial da psicologia históricocultural e da pedagogia histórico-crítica possibilita compreender que o conhecimento científico é base para a constituição da personalidade, pois estimula o pensamento por conceitos, que engloba o trabalho e a organização conjunta de todas as funções mentais superiores ou funções psíquicas superiores, formadas ao longo da vida, especialmente no período da adolescência (VIGOTSKI, 2007). 
Seguindo a linha teórica, Martins (2013, p. 275) adverte que "o desenvolvimento do pensamento se revela uma conquista advinda de condições que o promovam e o requeiram - e, como tal, depende em alto grau das dimensões qualitativas da formação escolar". Sendo assim, direcionar o pensamento dos alunos para que eles passem a pensar o mundo por intermédio de conceitos científicos é um compromisso da escola, e necessário para uma formação cultural e integral mais plena. Segundo a mesma autora,

uma educação escolar que vise à formação de indivíduos livres carece de primar pelo desenvolvimento do pensamento complexo, superior, na ausência do qual resultam comprometidos o ato volitivo e, igualmente, o autocontrole da conduta. É precisamente nesse âmbito que o ensino incide sobre a formação da personalidade. A formação de conceitos genuínos não intervém apenas no pensamento, já que para isso são requeridas diversas combinações funcionais que, em última instância, sustentam a maneira de ser da pessoa. Nisso reside o maior alcance do pensamento conceitual: a consciência da realidade e da própria personalidade (MARTINS, 2013, p. 304).

A personalidade humana desenvolve-se em sua plenitude quando há formação das funções mentais superiores que vão permitir o pensamento conceitual. A escola favorece a formação das funções mentais e da personalidade quando consegue fazer os alunos pensarem o mundo a partir de conhecimentos científicos (VIGOTSKI, 2007; MARTINS, 2013). Igualmente, a escola pode contribuir de outros modos para a constituição da personalidade, além da significação do conhecimento, conforme podemos depreender no registro de Pâmela: "nos espaços escolares aprendemos muito, não só conhecimento científico, mas a nos socializar, a nos desenvolver como ser humano, no convívio diário com a comunidade escolar sempre estamos adquirindo novas experiências que levamos para a vida" (Pâmela Questionário, 2019).

O depoimento de Pâmela introduz a discussão da nossa segunda categoria neste texto, que trata de implicações das (II) relações sociais no ambiente escolar para o desenvolvimento da personalidade humana. Algumas unidades de significado defendem que as relações sociais vivenciadas na escola implicam desenvolvimento da personalidade das pessoas. Essas evidências estão imbricadas no excerto a seguir:

na escola aprendemos a compartilhar espaço, materiais, tempo e vivências. Cada ser é único e admirável. A diversidade sociocultural dos indivíduos, que passam a fazer parte de nossa vida, nos enriquece de novos saberes, novas experiências. E o conhecimento científico somado ao sociocultural nos permitem ver o mundo com inúmeras formas e cores (Paulo - Questionário, 2019).

Em seu depoimento, além da relevância do conhecimento, Paulo destacou a importância das relações sociais que se estabelecem na escola para a constituição da personalidade. $\mathrm{O}$ referencial da psicologia histórico-cultural defende que as relações sociais definem o 
desenvolvimento humano e são decisivas na formação das funções superiores e na personalidade. Sendo assim, pensando o contexto escolar, "devemos perguntar como o meio social age na criança para criar nela as funções superiores de origem e natureza sociais" (SIRGADO, 2000, p. 52).

Seguindo esta linha de pensamento, emerge a reflexão de que um professor ensina mais do que conteúdos no percurso do trabalho educativo. Nas relações sociais que se estabelecem em sala de aula, entre alunos e alunos e entre alunos e professor, podem ser observados diferentes modelos de "ser pessoa". Na escola, a partir de interações com uma diversidade de pessoas, contextualizando diferentes signos e instrumentos da cultura, as crianças e adolescentes vão constituindo a si mesmos (VIGOTSKI, 2007). O docente demonstra aos seus alunos um modo de ser pessoa e de ser professor (NÓVOA, 1992). Algumas atitudes de professores podem revelar-se como um fator significante na vida dos alunos, influenciando na formação da personalidade. Nesse segmento, vale pensar sobre as seguintes proposições apontadas por Pedro durante a entrevista:

a gente está em um ambiente social e isso influencia a nossa formação. Talvez o que
a gente devesse... talvez o que a gente devesse fazer é refletir mais sobre qualé o papel
da escola na formação dessa personalidade. A escola tem que reforçar os
preconceitos? [...] Já aconteceu um caso em um colégio em que uma profe foi afastada
porque ela tratava os alunos com diferença. Ela botava o pessoal mais pobre, e que
talvez não tenha o costume do banho diário ou cuidado... sei lá! Quem passa fome vai
estar preocupado com sabonete?! Sabe? Entendeu? Crianças mais pobres eram
colocadas ao fundo [na sala de aula]. E as mais bonitinhas, as mais limpinhas, pessoal
filhos dos trabalhadores intermediários, ganhando 4,5 salários por mês, esse pessoal
ela colocava na frente [...]. Quando a direção percebeu esse tratamento, obviamente
agiu. [...] Então, que tipo de escola nós queremos?! (Pedro - Entrevista, 2020).

O episódio narrado por Pedro resplandece que na escola se desencadeiam algumas relações sociais, sadias ou não sadias, que podem favorecer ou dificultar a aprendizagem e o desenvolvimento cultural dos alunos. A fala de Pedro alerta para a necessidade de o professor refletir com criticidade em relação à sua própria postura para desempenhar um trabalho educativo, contextualizado conforme as circunstâncias do contexto em que está inserido. Anjos (2017, p. 11-12) lembra que "o adolescente necessita de modelo adulto de ser humano para o desenvolvimento da personalidade, do sentido de vida e da concepção de mundo". Por vezes, a maneira como o professor relaciona-se com seus alunos impacta nos processos de ensino e de aprendizagem, deixando marcas constitutivas na personalidade dos estudantes.

Não podemos negligenciar que é tarefa complexa desenvolver um trabalho educativo, especialmente com responsabilidade e amparo nos conhecimentos do referencial históricocultural e da pedagogia histórico-crítica. A escola não está dissociada da sociedade. Para parte 
da população brasileira, para situar um exemplo, o principal sentido da escola é a preparação para o mercado de trabalho. Em decorrência disso, o modelo de produção capitalista dominante na sociedade reflete tanto na forma de organização curricular quanto nos processos educativos e nas relações sociais nos espaços escolares. Marsiglia e Saccomani (2016), todavia, persuadem que

a escola atual, limitadora do máximo desenvolvimento humano, só poderá ser superada por uma nova organização social, da qual depende dialeticamente, a formação plena dos indivíduos. Assim, entendemos que cabe, neste momento histórico, atuar nas condições existentes, dominando todas as ferramentas que temos (como é o caso da periodização do desenvolvimento), para oferecer a melhor escola, o melhor ensino e a melhor educação, que proporcionem as condições adequadas para a superação do modo de produção capitalista. Em última instância, advogamos (com práticas educativas iluminadas pela psicologia histórico-cultural e pedagogia histórico-crítica) a formação de adultos e idosos que dominem a cultura naquilo que ela tenha de mais rico para que, assim, também enriqueçam sua existência como seres humanos: aptos a construírem condições objetivas de vida e capazes de transformar aquilo que precisa ser transformado (p. 365).

A partir da teoria proposta pelas autoras, tencionamos que as relações sociais que se desencadeiam no percurso de escolarização de cada pessoa são essenciais para o desenvolvimento da personalidade humana, e, concomitantemente, para a ascensão da cultura na sociedade. Na opinião de Pedro, "variados momentos da vida escolar contribuem para formar a personalidade, mas a qualidade desse processo depende da orientação e consciência da escola sobre isso" (Pedro - Questionário, 2019). Além do mais, notabilizamos que a qualidade da educação básica e o êxito do trabalho educativo não dependem somente dos esforços dos professores, como também é exposto na unidade de significado a seguir:

...ãh, que pergunta complicada, hein?!... como que eles [os alunos] poderiam se
desenvolver e compreender mais plenamente?! [pensando...] é, é complicada mesmo
essa pergunta. Porque na verdade o contexto... o contexto de cada aluno é diferente
um do outro, não é? Cada um traz a sua própria história, seus próprios saberes, traz
tudo junto. Então, nós temos que ter uma... um certo cuidado com isso, não é? A gente
tenta socializar, tenta fazer, ãh... cada um compreender a situação do outro. Mas,
assim, plenamente, eu acho que é meio complicado, sabe? A gente tenta, claro. Eu sou
uma professora que faço, procuro fazer, cada um respeitar, até questão religiosa, é
bem complicado se tu parar bem para pensar... no grupo social ali de alunos. Eu já
trabalhei Ensino Religioso com eles também. Ãh... por causa das diversas religiões.
Ãh... uns são do candomblé, outros são evangélicos, outros são católicos. Então,
assim óh: plenamente... a gente tenta. A gente tenta, mas conseguir já é outra
palavra" (Priscila - Entrevista, 2020).

As explanações de Pedro e Priscila atestam que os professores têm uma preocupação quanto à realização do trabalho educativo em prol da aprendizagem e do pleno desenvolvimento intelectual de seus alunos. Nesse sentido, Malanchen (2016, p. 219) pondera que "um currículo sob a luz da pedagogia histórico-crítica deve oferecer conteúdos que permitam ao ser humano 
objetivar-se de maneira social e consciente, de maneira cada vez mais livre e social". Nas declarações do contexto investigativo é apreensível, no entanto, que, por vezes não é de "sonhos" que a realidade se faz, como foi expresso anteriormente, pois "a qualidade desse processo depende da orientação e consciência da escola sobre isso" (Pedro - Questionário, 2019); e "assim óh: plenamente... a gente tenta. A gente tenta, mas conseguir já é outra palavra" (Priscila - Entrevista, 2020).

As locuções grifadas denunciam que nem sempre os professores têm as melhores condições de ordem formativa e instrumental nos espaços de trabalho para desempenhar sua função social, que implica formação social da personalidade de cada estudante. Os dizeres dos sujeitos de pesquisa também remetem à relevância de os professores estarem em constante estudo e reflexão crítica a fim de qualificar e transformar seu fazer docente. Os profissionais da educação necessitam produzir entendimentos sobre como o ser humano se desenvolve e como se constitui em personalidade no percurso histórico-cultural, considerando que "o quanto os indivíduos possam humanizar-se em seu processo de formação depende, é claro, das possibilidades concretas existentes para o gênero humano em cada momento histórico" (DUARTE, 2011 p. 340). A partir disso, aflora a defesa quanto à necessidade de haver mais investimentos públicos na qualificação dos processos formativos na docência, para que os professores tenham maiores possibilidades de promover um trabalho educativo contextualizado em seus campos de atuação profissional e, com isso, privilegiar aprendizagens e o desenvolvimento da personalidade na educação escolar.

\section{Algumas CONSIDERAÇões}

Os dados produzidos por ocasião desta pesquisa revelam que a educação escolar pode contribuir para a formação da personalidade humana, especialmente a partir de processos educativos que resultem na significação de conhecimentos científicos escolares. As manifestações dos sujeitos participantes também evidenciam que as relações sociais se apresentam como elemento essencial na condução do trabalho educativo e na constituição da personalidade, sendo um agente facilitador de aprendizagens e de desenvolvimento humano.

Com isso, compreendemos que a significação de conhecimentos e as relações sociais são fatores determinantes na constituição da personalidade dos estudantes. Essas referências, por sua vez, precisam estar imbricadas na construção de um trabalho educativo intencionalmente desenvolvido pelos professores em suas respectivas salas de aula. Em síntese, afirmamos que o trabalho educativo potencializa a constituição da personalidade humana no 
contexto escolar, à medida que ele tende a favorecer aprendizagens de conteúdos científicoescolares e o estabelecimento de interações mais sadias entre alunos e professores, mediadas por instrumentos e signos.

Finalizamos este artigo tendo clareza que a discussão da temática nele apresentada não pode se encerrar aqui. Defendemos que é preciso desenvolver outras investigações que direcionem para entendimentos mais aprofundados a respeito das contribuições da educação escolar na formação da personalidade humana. Nesse sentido, sinalizamos e nos comprometemos a dar continuidade a esta pesquisa.

Por hora, na condição de pesquisadoras, adiantamos que reconhecemos, a partir do referencial teórico e dos dados produzidos, a relevância de produzir e socializar conhecimentos específicos sobre implicações das atividades de estudo e de ensino desenvolvidas na educação escolar para a formação da personalidade humana. Com base no estudo construído até aqui, também desenvolvemos a percepção da importância de direcionarmos em artigos posteriores um maior empenho a fim de problematizar especialmente sobre o papel da afetividade nas relações sociais constituídas no âmbito do trabalho educativo, que implicam desenvolvimento global dos sujeitos que ocupam os espaços escolares. Partindo disso, num futuro próximo, esperamos poder socializar outros resultados do nosso processo investigativo que mobilizem reflexões críticas quanto à relação do trabalho educativo e à constituição da personalidade humana na educação escolar.

\section{REFERÊNCIAS}

ANJOS, Ricardo Eleutério dos. $\mathbf{O}$ desenvolvimento da personalidade na adolescência e a educação escolar: aportes teóricos da psicologia histórico-cultural e da pedagogia históricocrítica. 2017. Tese (Doutorado em Educação Escolar) - Universidade Estadual Paulista Júlio de Mesquita Filho, Faculdade de Ciências e Letras, Araraquara, SP, 2017.

BOZHÓVICH, Lydia. Las etapas de formación de la personalidad en la onteogénesis. In: La psicología evolutiva y pedagógica en la URSS. Moscú: Editorial Progreso, 1987.

BRASIL. Conselho Nacional de Saúde: Resolução No 510/2016. Brasília: Ministério da Saúde, 2016.

COPETTI, Camila et al. Análise textual discursiva em pesquisas no ensino de ciências e matemática: caminhos distintos e possíveis no processo de execução. Revista de Ensino de Ciências e Matemática, v. 11, n. 3, p. 85-104, 2020.

DUARTE, Newton. Vigotski e o aprender a aprender: críticas às apropriações neoliberais e pós-modernas da teoria vigotskiana. Campinas, SP: Autores Associados, 2011. 
EIDT, Nadia Mara; DUARTE, Newton. Contribuições da teoria da atividade para o debate sobre a natureza da atividade de ensino escolar. Psicologia da Educação, n. 24, p. 51-72, 2007.

LEONTIEV, Alexis Nikolaevich. O desenvolvimento do psiquismo. São Paulo, SP: Centauro, 1978.

LÜDKE, Menga; ANDRÉ, Marli. E. D. A. Pesquisa em educação: abordagens qualitativas. São Paulo: EPU, 1986.

MALANCHEN, Julia. Cultura, conhecimento e currículo: contribuições da pedagogia histórico-crítica. Campinas: Autores Associados, 2016.

MALDANER, Otavio Aloisio. A pesquisa como perspectiva de formação continuada do professor de química. Química Nova na Escola, v. 22, n. 2, p. 289-292, 1999.

MARSIGLIA, Ana Carolina Galvão; SACCOMANI, Maria Cláudia da Silva. Contribuições da periodização histórico-cultural do desenvolvimento para o trabalho pedagógico históricocrítico. In: MARTINS, Lígia Márcia; ABRANTES, Angelo Antonio; FACCI, Marilda Gonçalves Dias (org.). Periodização histórico-cultural do desenvolvimento psíquico: do nascimento à velhice. Campinas, SP: Autores Associados, 2016. p. 343-368. (Coleção educação contemporânea).

MARTINS, Lígia Márcia. O desenvolvimento do psiquismo e a educação escolar: contribuições à luz da psicologia histórico-cultural e da pedagogia histórico-crítica. Campinas, SP: Autores Associados, 2013.

MORAES, Roque; GALIAZZI, Maria do Carmo. Análise textual discursiva. 2. ed. Ijuí, RS: Unijuí, 2011.

NÓVOA, António Sampaio da. Os professores e as histórias da sua vida. In: NÓVOA, António Sampaio da. Vidas de professores. Porto, Portugal: Porto, 1992

SAVIANI, Dermeval. Pedagogia histórico-crítica: primeiras aproximações. 11. ed. São Paulo: Autores Associados, 2013.

SILVA, Lenice Heloísa de Arruda. A perspectiva histórico-cultural do desenvolvimento humano: ideias para estudo e investigação do desenvolvimento dos processos cognitivos em ciências. In: GÜLLICH, Roque Ismael da Costa Güllich (org.). Didática das ciências. Curitiba: Prismas, 2013.

SIRGADO, Angel Pino. O social e o cultural na obra de Vigotski. Educação \& Sociedade, v. 21, n 71, p. 45-78, 2000.

SMOLKA, Ana Luiza Bustamante. O (im)próprio e o (im)pertinente na apropriação das práticas sociais. Cadernos Cedes, a. Xx, n. 50, p. 26-40, 2000.

SMOLKA, Ana Luiza Bustamante. Sobre significação e sentido: uma contribuição à proposta de Rede de Significações. In: ROSSETTI-FERREIRA, Maria Clotilde et al. (org.). Rede de significações e o estudo do desenvolvimento humano. Porto Alegre: Artmed, 2004. 
VIGOTSKI, Lev Semenovich. A formação social da mente: o desenvolvimento dos processos psicológicos superiores. 7. ed. São Paulo: Martins Fontes, 2007.

VIGOTSKI, Lev Semenovich. Pensamento e linguagem. 4. ed. São Paulo: Martins Fontes, 2008.

VIGOTSKI, Lev Semenovich. Obras Escogidas. Madrid: Machado Grupo de Distribución, 2012a. Tomo III.

VIGOTSKI, Lev Semenovich. Obras Escogidas. Madrid: Machado Grupo de Distribución, 2012b. Tomo IV.

VIGOTSKI, Lev Semenovich; LURIA, Alexander Romanovich. Estudos sobre a história do comportamento: símios, homem primitivo e criança. Trad. Lólio Lourenço de Oliveira. Porto Alegre: Artes Médicas, 1996.

YIN, Robert K. Estudo de caso: planejamento e métodos. 2. ed. Porto Alegre: Bookman, 2001.

\section{Agradecimentos}

O trabalho foi realizado com apoio da Coordenação de Aperfeiçoamento de Pessoal de Nível Superior - Brasil (CAPES) - Código de Financiamento 001. 